\title{
Arterial Anastomosis in Living Donor Liver Transplantation
}

\author{
Mirela Patricia Sirbu Boeti, Vladislav Brašoveanu, \\ Sadiq Shoaib and Irinel Popescu \\ Fundeni Clinical Institute, \\ Department of General Surgery and Liver Transplantation \\ Romania
}

\section{Introduction}

Since the first successful operation in 1989, living donor liver transplantation (LDLT) for children with end-stage liver diseases has emerged as an alternative to cadaveric liver transplantation. (Strong et al., 1990) The applicability of LDLT was extended to adult patients in 1994. (Kiuchi et al., 1999) Justification of LDLT has evolved from increased organwaiting times, wait-list morbidity and mortality of transplant candidates. (Renz \& Busuttil, 2000) The left lobe or the left lateral segment of an adult liver is most often of adequate size for donation to a child recipient. However in the adult, the right hepatic lobe transplantation is usually the procedure of choice to provide adequate liver volume to the recipient. (Nakamura et al., 2002)

By having a thorough and accurate knowledge of vascular variants, the transplant surgeon can adopt the optimal techniques for vascular reconstruction, with the intent to provide an adequate inflow and outflow through liver parenchyma and to avoid postoperative vascular complications.

The present chapter reviews the surgical anatomy of the hepatic artery (HA), arterial reconstruction techniques as applied to LDLT, and postoperative arterial complications.

\section{Preoperative assessment of hepatic arterial anatomy}

Hepatic arterial anomalies are present in almost half of the living donors. (Macdonald et al., 2005) To accomplish a successful and uncomplicated operation, preoperative assessment of anatomy of hepatic vasculature is of paramount importance for both donor and recipient. Preoperative work-up may involve computed tomography (CT), ultrasonography (US) including Doppler imaging, magnetic resonance (MR) imaging, and catheter angiography.

Conventional angiography was substituted by three-dimensional computer tomography (3D $\mathrm{CT}$ ) angiography which is a safer, more convenient, cheaper, and better-tolerated procedure for determination of hepatic arterial anatomy. (Winter et al., 1995; Coskun et al., 2005)

CT has progressed from dual slice CT to 64-Multidetector Computed Tomography (MDCT) (Johnson \& Fishman, 2006), which represents a non-invasive technological advance that 
permits high-speed and high-resolution helical imaging of the entire liver volume during a single breath-hold. (Johnson \& Fishman, 2006)

CT angiography has become a key component of state-of-the-art imaging. The reconstruction of CT angiographic data sets obtained on 16- and 64-section scanners may result in 1000-5000 images per examination. The large size of the data set makes it impractical to extract all the information present by using standard two-dimensional techniques and makes clear the importance of volume imaging and 3D image display. (Fishman et al., 2006) The 3D high-quality reconstruction images are easy for post editing, and make possible to observe the origin, flow pattern and branches of the hepatic artery in fine anatomic details, from multiple angles, positions and layers, as well as adjacent structures. (Huang et al., 2009) Although 2D data sets show small arteries to better advantage than 3D multidetector CT angiography (MDCTA), the 3D MDCT angiograms provide a useful overview of hepatic anatomy. (Stemmler et al., 2004)

Radiologists now have workstations that provide capabilities for evaluation of these data sets by using a range of software programs and processing tools. Although different systems have unique capabilities and functionality, all provide the options of volume rendering (VR) and maximum intensity projection (MIP) for image display and analysis. In the MIP technique, only the pixel of highest intensity is used to calculate each line of pixel data through the viewed object and about $90 \%$ of data is discarded. A cine loop of multiple MIP images can be incorporated to facilitate determination of the vascular interrelations. In contrast, in the VR technique, all the helical CT data set is used for image reconstruction, thus multiple overlapping vessels, spatial relations between the arteries and the viscera, and arteries with small diameters can be displayed. (Fishman et al., 2006)

MDCT is a valuable evaluation of potential living liver donors because it provides an excellent pre-operative mapping of the hepatic arterial, hepatic, and portal venous systems of the potential donors prior LDLT, a comprehensive assessment of the liver parenchyma (e.g. fatty infiltration) and of many other intra-abdominal diseases or abnormalities, an accurate measurement of graft and remnant liver volume, and an excellent defining of the curved virtual hepatectomy plane that provides sufficient volume to satisfy the metabolic demands of both donors and recipients. (Alonso-Torres et al., 2005; Stemmler et al., 2004)

The most critical aspect of imaging potential liver donors is the accurate depiction of the origin and course of the artery to segment IV. Unlike currently available conventional helical scanners, MDCTA results in 1.25-mm resolution. If the acquisition parameters and timing of the contrast bolus are optimized, this resolution allows even a tiny artery to be viewed with minor interruption in adjacent slices or with no interruption in 3D models.

MR volumetry, venography, angiography, and cholangiography with 3D reconstruction is considered by some authors to be sufficient for all major imaging evaluation for LDLT. (Cheng et al., 2001, Sahani et al., 2004)

With the advantage of advanced imaging techniques used pretransplant, now it is possible to identify the anatomical type of hepatic artery (HA) according to Michels classification (Tabel 1).

There was no significant difference observed in the overall incidence of arterial complications between grafts with normal and abnormal anatomy. (Soin et al., 1996) Anomalies of hepatic arterial vasculature occur in one-third of all livers and do not 
compromise graft outcome unless multiple anastomoses or direct anastomosis to the recipient aorta are required for arterial reconstruction. (Soin et al., 1996)

\begin{tabular}{|l|l|}
\hline Type & Description \\
\hline I & Entire hepatic trunk arising from CHA \\
\hline II & Replaced LHA arising from LGA \\
\hline III & Replaced RHA arising from SMA \\
\hline IV & Replaced LHA and replaced RHA \\
\hline V & Accessory LHA arising from LGA \\
\hline VI & Accessory RHA arising from SMA \\
\hline VII & Accessory LHA and accessory RHA \\
\hline VIII & Replaced RHA and accessory LHA or replaced LHA and accessory RHA \\
\hline IX & Entire hepatic trunk arising from SMA \\
\hline X & Entire hepatic trunk arising from LGA \\
\hline
\end{tabular}

Table 1. Michels classification of the anatomical types of hepatic artery. (Michels, 1955 as cited in Coskun et al., 2005)

Hepatic arterial branching patterns do not correlate well with the presence of anomalous biliary drainage. In patients with normal hepatic vascular anatomy, biliary anomalies are more frequent than in those with anomalous vascular anatomy (50\% versus $30 \%$ ). (Macdonald et al., 2005) Arterial blood supply to the left lobe often shows variations such as multiple branches, aberrant left hepatic artery (Sakamoto et al., 2002), whereas the right hepatic artery is often unique. (Kishi et al., 2004) Anatomic variations in graft hepatic arteries are classified by Takatsuki et al. into 3 types (Figure 1): Type I, single pedicle with (Ia) or without (Ib) aberrant artery (left hepatic artery (HA) from the left gastric artery or right HA from the superior mesenteric artery); Type II, double pedicles with (2a) or without (2b) aberrant artery; and Type III, equal to or more than three pedicles. (Takatsuki et al., 2006) The arterial reconstruction is anticipated based on this classification. Type I of arterial vasculature will allow the reconstruction of only one artery. Type II and III will necessitate a very careful intraoperative assessment of the arterial flow and an elaborated decision for the arterial reconstruction.

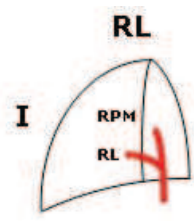

LL

I

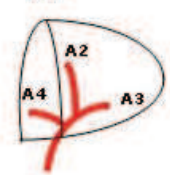

II

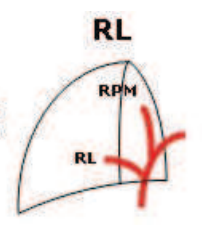

LL

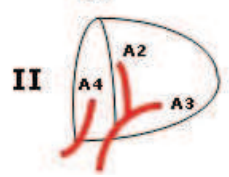

II

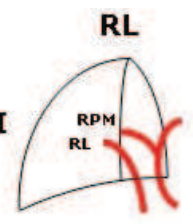

LL

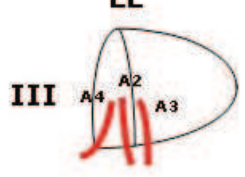

Fig. 1. Type I, single pedicle; Type II, double pedicles; and Type III, equal to or more than three pedicles. RL - right lobe, LL - left liver (modified after Takatsuki et al., 2006) 
A rare anatomical variant is worth mentioning. In Fig. 2 it is depicted a communication between a normal right medial arterial branch emerging from proper hepatic artery and a replaced right lateral arterial branch emerging from superior mesenteric artery. This communication is favorable by avoiding the reconstruction of both branches. Both branches are cut proximal to the interconnection. Only the larger donor's artery is used to perform the arterial anastomosis with the receptor's proper hepatic artery.
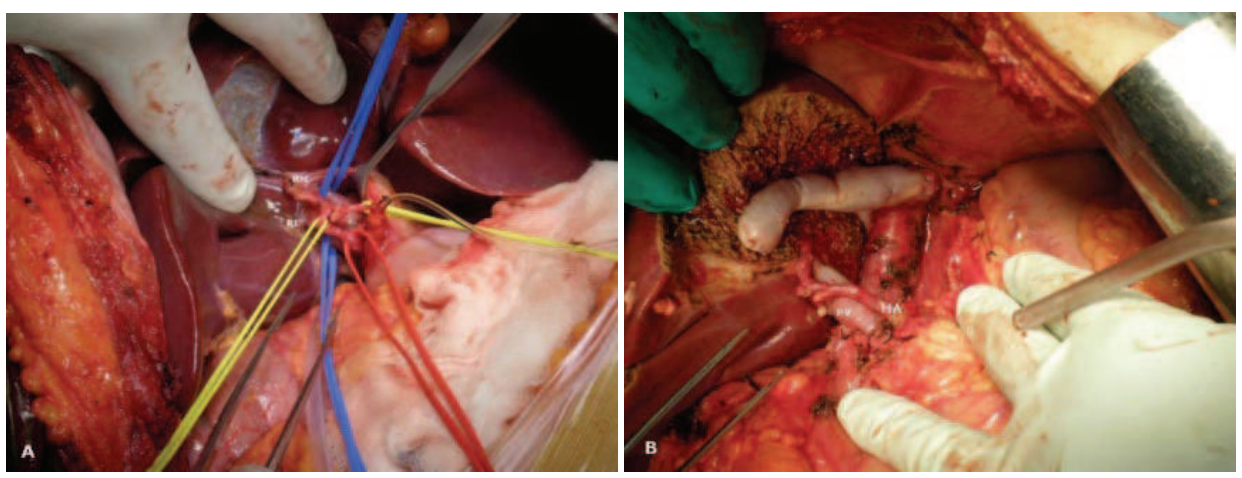

Fig. 2. A) Dissection of hepatic hilum with the identification of a communication between a normal right medial arterial branch emerging from proper hepatic artery and a replaced right lateral arterial branch emerging from superior mesenteric artery. B) Arterial anastomosis is completed between the donor's hepatic branch from superior mesenteric artery and recipient's proper hepatic artery

\section{Reconstruction techniques of the liver arterial vasculature}

During hilar dissection in donor operation, the HA and portal vein of the donor are individually exposed and carefully divided. In left grafts, the proper HA is exposed up to the bifurcation of the left (or middle) HA and the right HA. In right grafts, the right HA is identified and isolated to the right side of the hepatic duct. The division point of HA is determined by the length and size of the artery, its relationship with the cutting plane of the liver, and the position of the arteries. (Takatsuki et al., 2006) Division of the donor vessels at a point further distal to the main trunk than would be considered ideal for donor protection. Anastomosis of first- or second-order vascular branches is a requirement of LDLT. (Marcos et al., 2001)

The reconstruction technique of the liver arterial vasculature is selected by the surgeon based on the anatomical arterial variants, differences in vessel caliber, length and quality of recipient HA (i.e. aneurysm, stenosis, intimal dissection, inflammation of the porta hepatis, inadvertent injury of donor or recipient HA).

In the recipient, HA reconstruction is carried out after reconstructing of both hepatic and portal veins followed by the reperfusion of the implanted graft. In liver transplantation arterial reconstruction is essential to ensure a good blood inflow for proper graft function. The absence of an adequate hepatic arterial supply usually results in graft loss due to biliary ischemia and parenchymal complications. Hepatic arterial reconstruction in LDLT is technically more difficult and troublesome than in orthotopic liver transplantation (OLT), 
mainly because of the need to reconstruct thin, short, and/or multiple arterial branches in limited surgical fields. Moreover the hilar structures lie in a different plane than native vessels, and optimal realignment for anastomosis is sometimes impossible to achieve. Reconstruction under these circumstances requires an unusual degree of precision. (Marcos et al., 2001)

Microsurgical reconstruction of the liver vasculature in LDLT rises significant challenges to the surgeon. There are various aspects to be addressed: (1) difficulty in obtaining a good operative field and a sufficient view through the microscope due to the deep location of the liver in the abdominal cavity; (2) the respiratory movement and heart pulsation; (3) vesselsize discrepancy between the graft and recipient hepatic arterial stumps; (4) possible intimal dissection and atheromatosis, small caliber, and/or short stalk of the donor hepatic artery/arteries.

Longer microsurgical instruments are required to get an easier access. One or two soft suction tubes are placed at both sides of the HA to provide a bloodless operative field. When an operating microscope is used, it is draped with a sterile plastic bag and adjusted as the operator stand at the patient's right side and the assistant stand at patient's left side. HA in LDLT can also be safely reconstructed with microsurgical techniques without microscope using, with 6x loupe magnification. (Enne et al., 2010; Guarrera et al., 2004) To provide a wide anastomosis and consecutively to avoid microscope usage, native and graft hepatic arteries can be spatulated from both the anterior and posterior walls. (Haberal et al., 2007)

To overcome large movement caused by respiration, the suturing of the hepatic arteries should be synchronized according to the rhythmic chest wall up-and-down movement. If this has not the expected result, a decrease of the tidal volume to $300-400 \mathrm{~mL} / \mathrm{min}$ may help. An alternative stabilization of the operative field is to use smooth manual bagging technique instead of mechanical ventilation.

In most cases the caliber discrepancy is dealt with simple methods such as gently dilatation of the vessel edge, enlargement of the circumference of the smaller lumen by cutting artery obliquely or in fish-mouth, making a longitudinal side-cut, funnelization, suturing with wider bites on the larger vessel. (Inomoto et al., 1996) When the size mismatch is greater than 1:3, the alternatives are: the interposition of an arterial graft (e.g. superior rectal artery, ovarian artery, radial artery (Kamei et al., 2006)) or venous conduct, the construction of an end-to-side anastomosis or anastomosis with a side branch of the larger vessel. When a discrepancy in the thickness of the vessel walls is encountered, full bites of the thinner vessel and only inner layers of the thicker vessel should be taken in the sutures.

Multiple arterial tributaries in right liver graft procurement are rare. Due to its anatomic characteristics RHA anastomosis is relatively straightforward (Marcos et al., 2000) with no complications and is often aided only by loupe magnification, sometimes using an artifice. (Di Benedetto et al., 2004) In case of a very short right arterial stump in the graft, there are two options: (1) the use of microsurgical techniques with double needle threads; (2) the interposition technique proposed as a reversed extension graft. Harvesting an arterial graft for interposition will subject either the donors or recipients to an additional incision or more extensive dissection and prolonged operation time with consecutive increased risk of 
thrombosis in the recipient. Thus the arterial conduct interposition should be avoided as much as possible.

It is still debated in LDLT whether all arterial stumps should be anastomosed. However a simple method of only one anastomosis is sufficient if backflow from another tributary is confirmed, indicating that a compensation of arterial perfusion exists in both left (Ikegami et al., 1996) and right liver grafts (Kishi et al., 2004). When backflow from the second tributary is absent, this artery should be reconstructed. (Marcos et al., 2001)

Different from the right lobe, multiple arteries to the left lobe are rather common, and care must be taken when harvesting the graft in such cases. Incidence of HA thrombosis was showed to be four times higher in the grafts with multiple arteries than those with a single artery. When encountering dual arteries during donor surgery, there are three options to be considered: (1) division of both arteries and reconstruction of only one; (2) division and reconstruction of both arteries; (3) 2-in-1 segmental resection followed by donor HA reconstruction.

The arterial reconstruction is sometimes needed in the donor when a 2-in-1 segmental resection is performed and, as in the recipient, it is of paramount concern. The incidence of arterial occlusion after reconstruction in the donor HA must be lower than in the recipient in order to address the most important ethical issue of LDLT - donor safety.

The average diameters of the stump of the graft and recipient's arteries are 2.5-0.5 $\mathrm{mm}$ and the average of these caliber differences are $0.3-0.5 \mathrm{~mm}$. The end-to-end arterial anastomosis is the choice whenever possible. Depending on the diameter of the vessels, the surgeon has to choose between loupe and microscope. The use of microvascular techniques has revolutionized reconstruction and expanded the range of options for reconstructing small and incongruent arteries. Microsurgery is complex and technically demanding, but with careful preparation and proper execution, it has been proved beneficial to the patient and rewarding to the surgeon. (Inomoto et al., 1996)

Arterial anastomoses in the left lobe and left lateral segment living donor transplantation incur a relative frequent complication rate when performed by loupe magnification but a significant lower incidence of these when microvascular techniques are used. By using the microscope, a fine hepatic artery less than $2 \mathrm{~mm}$ in diameter is no longer regarded as a contraindication for LDLT due to the potential arterial complications. (Inomoto et al., 1995)

The graft should be prepared in such a way that only one arterial anastomosis is performed in order to avoid the risk of thrombosis. The single independent arterial anastomosis technique is most commonly used for arterial anastomosis in LVLT.

After preparing the graft for anastomosis, the fitness of each arterial branch should be assess for microvascular reconstruction. In this assessment the quality of the recipient hepatic artery should be inspected carefully using the high power of microscope. The interior of vessel should be observed for signs of intimal irregularity such as separation from the media due to preexisting conditions (e.g. atherosclerosis, previous surgical trauma). Any sign of damage indicates the need for further debridement. After adequate debridement, there should be a strong pulsatile flow from the recipient artery. After assessment of quality of arteries, the length and caliber matching should be carefully observed. 
The difficulty related to correct match of vessels diameter is present mostly in pediatric LDLA cases where the caliber of the graft artery is smaller than that of the recipient hepatic artery. In most cases the caliber difference is dealt with simple methods such as gently dilatation of the vessel edge, oblique cutting of the graft artery, fish-mouth method, and short longitudinal incision. Funnelization is an appropriate method to accommodate a much wider size disparity by enlarging the circumference of the smaller lumen.

In LDLT graft HAs are usually reconstructed with a recipient HA branch (anatomical HA reconstruction). Surgeons often encounter difficulties in extra-anatomical HA reconstruction, when a recipient artery other than a HA branch must be used. When biliary reconstruction is chosen to be performed by duct-to-duct anastomosis, recipient's left HAs should be selected for HA reconstruction in right liver LDLT in order to decrease the rate of septic and biliary complication. (Uchiyama et al., 2010) In extra-anatomical HA reconstructions, the arteries used are right gastroepiplooic artery, gastric artery, gastroduodenal artery, left gastric artery, splenic artery, cystic artery (Lee et al., 2008), and infrarenal abdominal aorta (Uchiyama et al., 2010).

The single independent arterial anastomosis can be performed with or without interposition graft depending on the condition of arteries that are to be anastomosed. When the intimal condition, length, and diameter of the recipient and donor artery are appropriate to each other then the single independent arterial anastomosis without interposition graft is performed in an end-to-end fashion in LDLT.

In almost all the situations vessel anastomosis in recipient is performed in end-to-end fashion using interrupted sutures. For a HA with a diameter of at least $3.0 \mathrm{~mm}, 8-0$ suture is indicated. For a HA with a diameter less than $3.0 \mathrm{~mm}, 9-0$ suture is indicated (Okochi $\mathrm{M}$ et al., 2010). The monofilament suture can be nylon (Ethilon; Ehicon Inc, Somerville, NJ) or polypropylene (Prolene; Ehicon Inc, Somerville, NJ). Less frequently, arterial anastomoses are performed using continuous suturing. The reason to avoid continuous suturing is to minimize narrowing of the arterial lumen. Some authors describe the placement of continuous suture on the posterior wall and interrupted sutures on the anterior wall. (Okochi M et al., 2010)

An alternative surgical technique that avoids interpositional vessel grafts or tension on the connection is successfully used by some authors. An end-to-side anastomosis is performed between allograft hepatic vein and recipient inferior vena cava in a more caudate location. The level of venotomy on the recipient vena cava is decided according to the preanastomotic placement of the allograft in the recipient hepatectomy site with sufficient width to have a hepatic artery anastomosis without tension or need for an interposition graft during hepatic artery and portal vein anastomoses. (Ersozet et al., 2003)

There are various techniques applicable for hepatic arterial reconstruction.

1. The double clip-fixation technique is feasible when the donor arterial stump is long enough to allow to turn over the vessels after the completion of the anterior wall of the anastomosis. The double micro-clamp is applied first to the donor HA then the recipient HA and a silastic background is placed behind the hepatic vessels.

2. The two stay suture technique is performed without using a double clip. Two stay sutures are placed $180^{\circ}$ apart at the center of the anterior and posterior walls, left untied, 
3. and retracted gently to keep the anastomotic site in the best position. Some sutures are placed on one lateral side between the stay sutures, and left untied to ensure precise placement of the sutures in the direct view of the lumen. After all these side sutures are placed, they are tied. Next, the two stay sutures are turned over $180^{\circ}$ and retracted in the opposite direction, and the other lateral side sutures are placed in the same manner. The anastomosis is completed by tying the stay sutures.

4. The doubly-armed microsuture technique or back wall support suture technique is recommended to avoid the twisting during suturing and thus to overcome the drawbacks of the conventional method performed in a deep abdominal cavity and/or on a short hepatic artery with no possibility for turning of the microclamps. (Ikegamiet et al., 2000) Microvascular anastomosis without turning over the clamp is considered by some authors superior to the conventional method in terms of reducing intimal damage to the vessels. (Yamamoto et al., 1999) Back wall-first approach should be favored especially when dealing with a fragile HA due to age, liver disease, atherosclerosis or post-transcatheter interventions such as arterial embolization in hepatocellular carcinoma before transplant. (Takatsuki et al, 2006) The recipient and graft arteries are clamped with single microclamps. The first double needle 9-0 monofilament microsuture is placed at the most difficult point (usually at the middle of the posterior wall) in the artery to be visualized through the microscope. Each stitch is always placed from the inner side of the arterial wall to the outer side. The posterior stitch is tied pulling toward the back. The subsequent sutures are advanced anteriorly on either side adjacent to the previous suture. The anterior vessel wall is sutured with a regular microsuture with a single needle. (Miyagi et al, 2008)

5. The branch patch anastomosis for hepatic arteries uses the bifurcation of hepatic arterial branches. The bifurcation of the arteries are cut longitudinally and then the plasty is performed to make a patch. To create a large orifice for the arterial anastomosis, the short part of the patch is wrapped with a long flap of the arteries from the other side. Cystic artery bifurcation from right hepatic artery can also be used to prepare a patch to be anastomosed to the recipient right branch of the hepatic artery. (Di Benedetto et al., 2004) During the procedure, a small vascular catheter can be used as a guide inside the gastroduodenal artery (GDA) which then is removed at the end of the anastomosis, as the GDA itself is sutured.

6. The technique of the ex situ reconstruction with a Y-extension graft is suited for the complex situation of double hepatic arteries. In the case of a donor graft with two arteries, the Y-extension graft procedure appears to be necessary. (Marcos et al., 2001, 2003) The recipient's HA is dissected well beyond both the right and left hepatic arteries which are transected to obtain the Y-extension graft. The artery is transected just distal to the takeoff of the gastroduodenal artery while the recipient liver continues to be perfused by portal blood flow during ex situ reconstruction of the arteries. Because arterial inflow to the recipient common bile duct may be sacrificed, duct-to-duct biliary reconstruction is contraindicated.

On back table the right and left hepatic arteries are anastomosed with interrupted sutures to the dual arterial system on the donor right lobe under loupe magnification. The patency and integrity of the anastomoses are reassessed through the free end of the vascular conduit before engraftment. The free end of the Y-extension graft (proper hepatic artery) is sutured in situ to the recipient hepatic artery branched cuff of the common hepatic artery and gastroduodenal artery. The wide lumen created by branch 
patching usually allows for running anastomosis with 5-0 or 6-0 prolene suture (Figure 3). (Marcos et al., 2001)

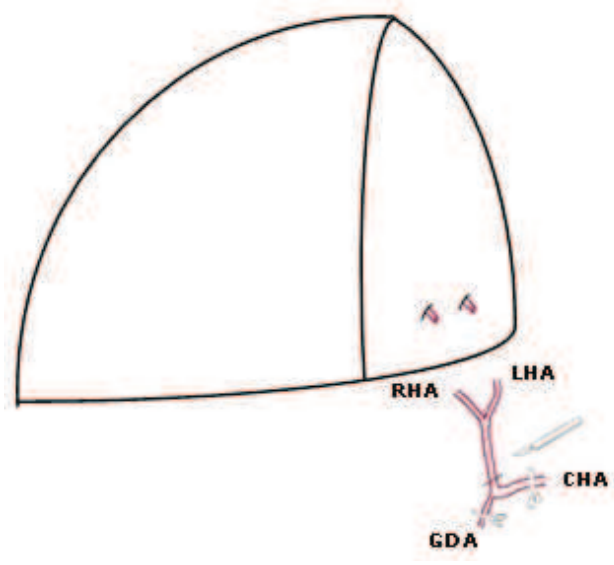

(a)

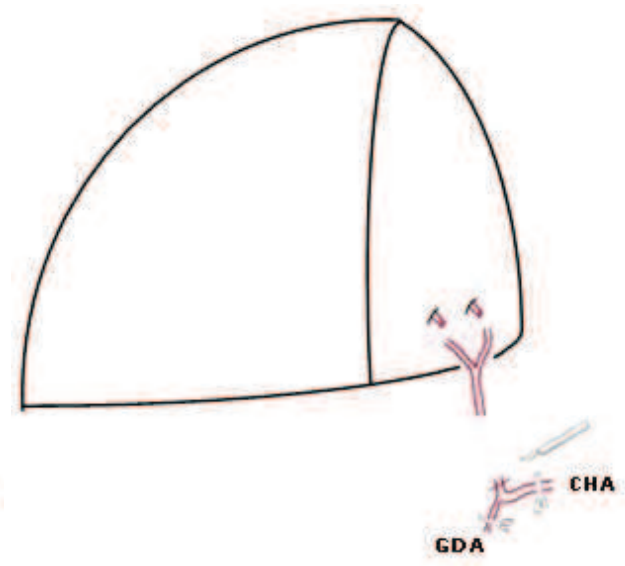

(b)

Fig. 3. Reconstruction of two right hepatic branches. A. Recipient's right, left, and proper hepatic arteries are sectioned to obtain a Y-vascular graft. The level of section of proper hepatic artery is at the takeoff of gastroduodenal artery. B. The arterial branches of the hepatic graft are anastomosed on table using the bifurcation of Y-graft. The free end of the Y-graft is anastomosed at the bifurcation of common hepatic artery

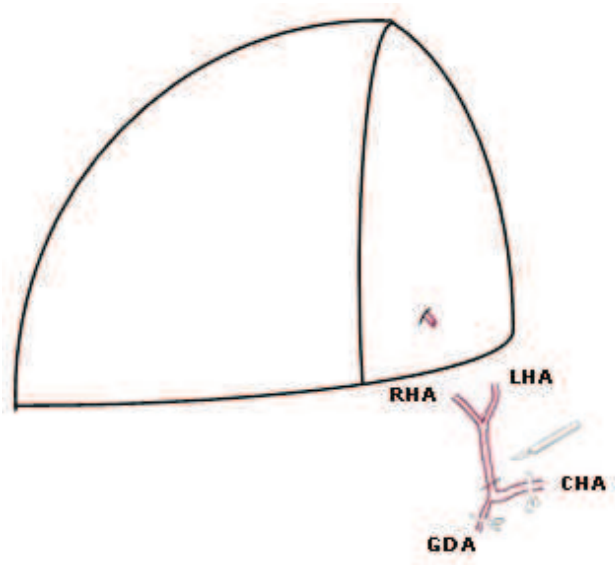

(a)
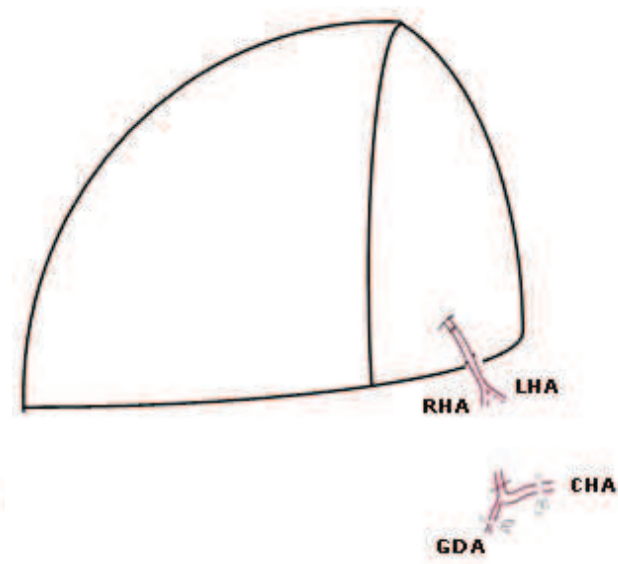

(b)

Fig. 4. Reconstruction of a short right hepatic artery. A. Right, left, and proper hepatic arteries are sectioned to obtain a Y-vascular graft. The level of section of proper hepatic artery is at the takeoff of gastroduodenal artery. B. The free end of Y-graft is anastomosed with the right hepatic artery of the graft on back table. The branches of Y-graft are cut at the bifurcation to obtain a larger lumen that will be anastomosed with the bifurcation of recipient's common hepatic artery 
7. The reversed extension bifurcated graft technique is a standard technique for single arterial anastomosis in the recipients. The modification begins with the dissection of the recipient hepatic artery well beyond the bifurcation of the RHA and LHA.

The proper hepatic artery is transected just distal to the takeoff of the gastroduodenal artery from the common hepatic artery while the recipient liver continues to receive portal perfusion. The bifurcation of the RHA and LHA is opened to create a wider bifurcated cuff. Then the arterial segment is reversed so that the once-proximal end of the PHA is sutured to the donor graft RHA under direct vision ex situ, and tension free, with interrupted 7-0 prolene. The reversed bifurcated (RHA/LHA) graft, with its new arterial extension, is then anastomosed to the larger branched cuff of the CHA and GDA using standard branch-patch technique (Figure 4). (Marcos et al., 2003)

8. The ex situ graft extension is another feasible and alternative technique for reconstruction of hepatic artery in LDLT if there are issues regarding length, size discrepancy or reconstruction of more than one artery. (Marcos et al., 2003) From cadaveric grafts it can be used internal and external iliac artery, splenic artery, reversed saphenous vein, and superior mesenteric artery. The SMA has proved particularly useful to overcome large size discrepancies and also reconstruct multiple arteries into a single vessel. Splenic artery can be ligated because the short gastrosplenic vessels and the left gastric artery maintain the vascularization of the spleen. However the risk of splenic infarction exists especially in case of a large spleen. (Lehar et al., 1990) The right gastroepiplooic artery can be dissected free from the greater curvature of the stomach and the surrounding tissue without causing ischemia of the stomach. An end-to-end anastomosis between this artery and the donor hepatic artery can be performed. The major disadvantage of any interpositional graft is that it needs two anastomosis to be performed which may lead toward increased risk of HAT. Anastomosis to the recipient's common hepatic artery resulted in a high incidence of thrombosis, whereas anastomosis to the infrarenal aorta nearly always remained patent, regardless of the length of the interposition of the saphenous vein. The inferior mesenteric vein can also be used for the arterial reconstruction. (Margreiter et al., 2008) There is a high risk for the inferior mesenteric vein to become ectatic when exposed to arterial pressure, which causes turbulence, and thrombosis may result. (Broelsch et al., 1999)

9. The superior mesenteric artery branch of Roux-en-Y limb technique is an alternative when porta hepatis inflammation makes difficult to use the hepatic, gastroduodenal or right gastroepiplooic artery for hepatic arterial reconstruction, or when a subintimal dissection or atheromatosis extends to all tributaries of the celiac arterial trunk. (Kasahara et al., 2005) A jejunal arterial arcade of Roux-en-Y limb mobilized for biliary reconstruction is anastomosed to the donor hepatic artery in end-to-end fashion. (Ikegami, et al., 2008) The arterial reconstruction in Roux-en-Y hepaticojejunostomy technique is performed before biliary reconstruction (Figure 5).

10. When multiple graft arteries are encountered, the dominant artery is reconstructed first. The dominant HA in grafts with multiple hepatic arteries can be determined by comparing arterial flows during intraoperative DUS after temporary occlusion of each artery using microvascular clips in the donor operation. This is followed by careful check-up on back-bleeding from the other arteries. If back-bleeding is insufficient both arteries must be reconstructed. Despite the fact that complex HA reconstructions are needed in such circumstances, with technical advancement, HA-related complications can be avoided in most cases. (Uchiyama et al., 2010) If back-bleeding is sufficient, the 
unreconstructed arteries can be ligated. The blood flow through the vessel anastomosis is verified by color flow DUS.

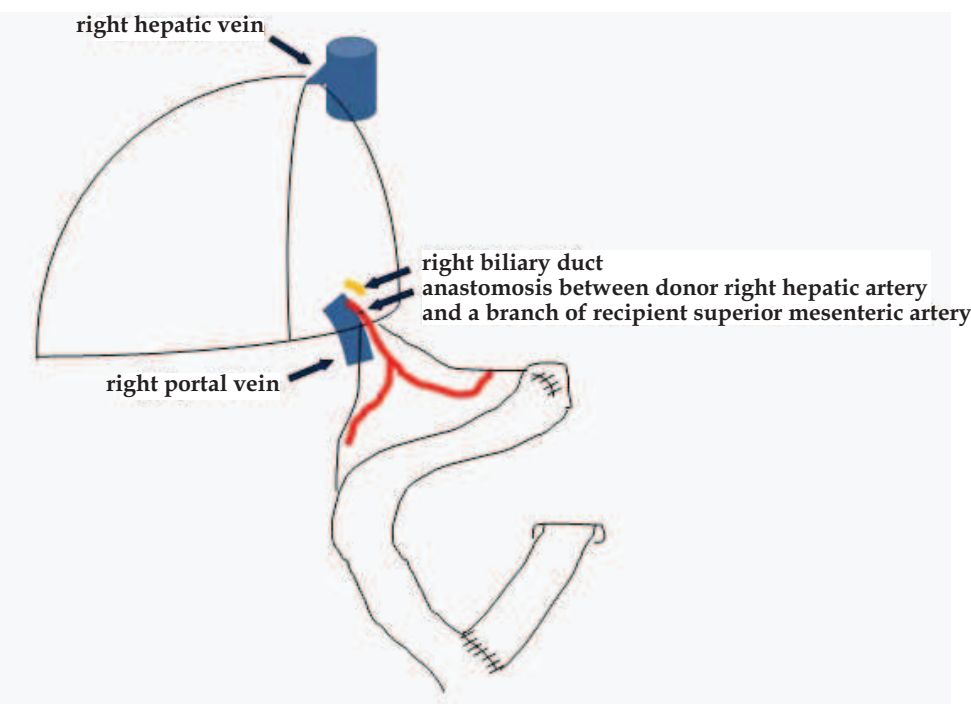

Fig. 5. A segment of jejunum is mobilized. An arterial branch of superior mesenteric artery of Roux-en-Y limb is anastomosed with the arterial stump of the liver graft. Biliary anastomosis is performed after arterial reconstructions

In rare case of right graft dual arterial supply the anastomosis of the larger branch is made first, then the backflow is checked from the smaller branch. If not good, the smaller branch must be reconstructed. The cystic artery can be used as a conduit for the reconstruction. The length of cystic artery is preserved as long as possible. The cystic arterial stump is anastomosed to the stump of the posterior branch the of RHA under microscopic guidance on the back table. Patency is checked through the stump of the anterior branch of the RHA. With this technique, only one orifice, the stump of right anterior hepatic artery, is used for hepatic artery reconstruction. (Lee et al., 2008)

In case of left graft dual arterial supply Douard et al. use a two-step strategy for the development of flow-induced enlargement of a small diameter artery. The smaller arterial branch is ligated during a laparoscopic first-step procedure to induce a $30 \%$ enlargement of the remaining branch. The second-step donor hepatectomy is performed one week later using a larger artery for successful vascular anastomosis. (Douard et al., 2002) It is worth underlining the importance of preoperative imaging for the identification of anatomic vascular variants which can be addressed in two-step strategy. The same authors reported a case with angiographic revealed celiac trunk compression by the median arcuate ligament and reverse vascularization of the middle hepatic artery via the gastroduodenal artery, a proper hepatic artery $2 \mathrm{~mm}$ in diameter irrigating the left lateral segment exclusively, and a right hepatic artery irrigating the right lobe and segment IV. First-step division of the median arcuate ligament and gastroduodenal artery ligation was followed by a repeat angiography at the third week showing a 50\% enlargement of the middle hepatic artery $(3 \mathrm{~mm})$ and the second-step left lobectomy performed at the fifth week. (Douard et al., 2002) 
Upon completion of the arterial anastomosis the distal clamp is released first and any major leaks should be dealt with by reapplying the clamp, irrigating, and inserting additional sutures.

\section{Posttransplant arterial complications}

In the early days of LDLT, the primary cause of postsurgical hepatic ischemia and failure used to be acute thrombosis of the HA with consecutive ischemia of the bile ducts and patch necrosis of the graft. Later, anastomotic stenosis of the HA has also been recognized as an important cause of posttransplant liver ischemia. An additional cause of graft ischemia is arterial steal syndrome, in which liver ischemia is caused by reduced blood flow through the HA rather than by obstruction. Other arterial complications are arterio-venous fistulas, anastomotic leakage, and intimal dissection.

Multivariate analysis of cases revealed that microsurgical experience was the only significant factor in reducing the incidence of HA complications in LDLT. (Matsuda et al., 2006)

In the face of donor organ shortage and high mortality related to liver re-transplantation, earlier detection of arterial complications using various imaging techniques followed by prompt revascularization as an alternative to re-transplant is very important.

\subsection{Hepatic artery thrombosis (HAT)}

Hepatic artery thrombosis (HAT) still remains the most devastating event that may occur in patients after LDLT, with a higher incidence than in patients with OLT. HAT most commonly occurs within the first postoperative week. There are three clinical presentations of the patient with HAT. The first one is fulminant hepatic necrosis with rapid clinical deterioration. In this situation HAT is the primary concern and the diagnosis should be actively pursued even when the US finding is negative. If focal parenchymal alterations such as infarcts or abscesses are seen with US, the diagnosis is certain in $90 \%$ cases. This is invariably fatal without transplantation. The second clinical presentation is the development of a delayed bile leak due to ischemic necrosis of the bile duct, a direct result of the HAT. Subhepatic fluid collections, frank bile peritonitis, bacteremia, and sepsis may occur. In milder cases, episodes of cholangitis, bile duct strictures, or segmental biliary dilatation are encountered. The third clinical presentation consists in relapsing bacteremia, gastrointestinal bleeding, fever of unknown origin, coagulopathy, or unexplained increase in liver enzymes.

When compared to adults, children have been reported to be at greater risk for HAT after pediatric LDLT due to small arterial size, nonuse of intraoperative microscope, and postoperative hypercoagulable state. LT recipients diagnosed with HAT have a relative risk of $90 \%$ for developing biliary complications. Up to $50 \%$ of patients with HAT may require retransplantation.

Surgical technique remains the primary cause for HAT, especially if thrombosis occurs within 2 months since transplantation. Surgical risk factors include small volume of graft or small arterial size in donor and/or recipient [specifically small recipient $(<10 \mathrm{~kg}$ or $<15 \mathrm{~kg}$ ) or recipient artery $(<3 \mathrm{~mm})]$, disparity in hepatic artery diameter between donor and 
recipient, the use of interposition, and tight anastomosis. In this category are also mentioned changes in hepatic arterial flow caused by tension, twisting, kinking, or compression of the vascular pedicle. Incriminated non-surgical causes for HAT are ABO-incompatible graft, anticardiolipin antibody in the recipient, cigarette smoking, prolonged cold ischemic time, acute rejection episodes, excessive intraoperative transfusion of clotting factor, coagulation abnormalities including heritable thrombophilia, absence of postoperative prophylactic anticoagulation, over-transfusion of fresh frozen plasma, high hematocrit levels, low donor/recipient age ratio, re-transplantation, and CMV infection.

The incidence of HAT has been reduced not only with the use of new and innovative surgical and microsurgical techniques (Aramaki et al., 2006) (Uchiyama et al., 2002), but also with posttransplantation administration of heparin, aspirin, alprostadil (PGE) (Heffron, et al., 2003), and/or gabexate mesilate (Miyagi et al., 2010). Overtransfusion of fresh-frozen plasma in high-risk patients (ABO incompatible) may be a critical factor in the development of HAT in LDLT. (Hatano et al., 1997) Although HA thrombosis is not always due to technical causes, some authors believe that when anastomosis is done correctly, no additional medication is necessary. (Takatsuki et al., 2006)

A proposed administration regime for heparin is $200 \mathrm{U} / \mathrm{kg}$ of body weight per day for a period of 14 days. Administration of single dose of aspirin as low as $3 \mathrm{mg} / \mathrm{kg}$ will inactivate circulating platelets by acetylating the enzyme cyclooxigenase present in platelet wall and has a beneficial effect on anastomosis patency. Some authors proved that anticoagulation utilizing ASA and alprostadil is sufficient to avoid HAT in pediatric recepients. (Heffron et al., 2003) Dextran can be administered as $500 \mathrm{~mL}$ over 5 to 6 hours once daily for 3 to 5 days or $500 \mathrm{~mL}$ slowly over a 24 hour period. The allergic reactions can be avoided by administration of dextran 1 instead of dextran 40 . When gabexate mesilate was administered as full-dose of $40 \mathrm{mg} / \mathrm{kg} /$ day no HAT occured. (Miyagi et al., 2010)

Doppler ultrasound (DUS) has been accepted as the best diagnostic tool for HAT and has surpassed angiography, which is invasive and time-consuming. Upon the completion of arterial anastomosis in LDLT an immediate intraoperative ultrasonography (IOUS) with 8$12-\mathrm{MHz}$ linear transducer is mandatory both on gray-scale and Doppler study. HA anastomosis is identified on gray-scale US, and the diameter and percentage of stenosis of the anastomosis is measured. The HA is also evaluated to detect thrombus or dissection in the region of anastomosis. Doppler study of the graft HA is performed to search for the abnormal parameters (e.g. peak systolic velocity $<30 \mathrm{~cm} / \mathrm{s}$ or $>2 \mathrm{~m} / \mathrm{s}$, resistive index (RI) < 0.5 , and systolic acceleration time $>80 \mathrm{msec}$ ). (Mun et al., 2010) Intraoperative identification of arterial complication may impose arterial reanastomosis (Figure 6).

The sonographist must know the details of arterial anastomosis. In patients making an uneventful recovery, the arterial velocity tended to increase and the resistive index to decrease during the first postoperative week. (Stell et al., 2004) The peak systolic velocities, end-diastolic velocities, and resistive indices are associated with the length and caliber of the type of hepatic artery anastomosis used. End-to-end anastomoses are short and have a uniform small caliber; aortohepatic bypasses are longer and have a progressively by smaller caliber. (De Candia et al., 2002)

The normal hepatic artery shows a hepatopedal flow, with a systolic flow maximum greater than $30 \mathrm{~cm} / \mathrm{sec}$ (Broering et al., 2004), a rapid systolic upstroke with an acceleration time 
(time from end diastole to the first systolic peak) of less than $100 \mathrm{msec}$, and a continuous flow through diastole with a resistive index between 0.5 and 0.7 (Muradali \& Wilson, 2005) (Figure 7).

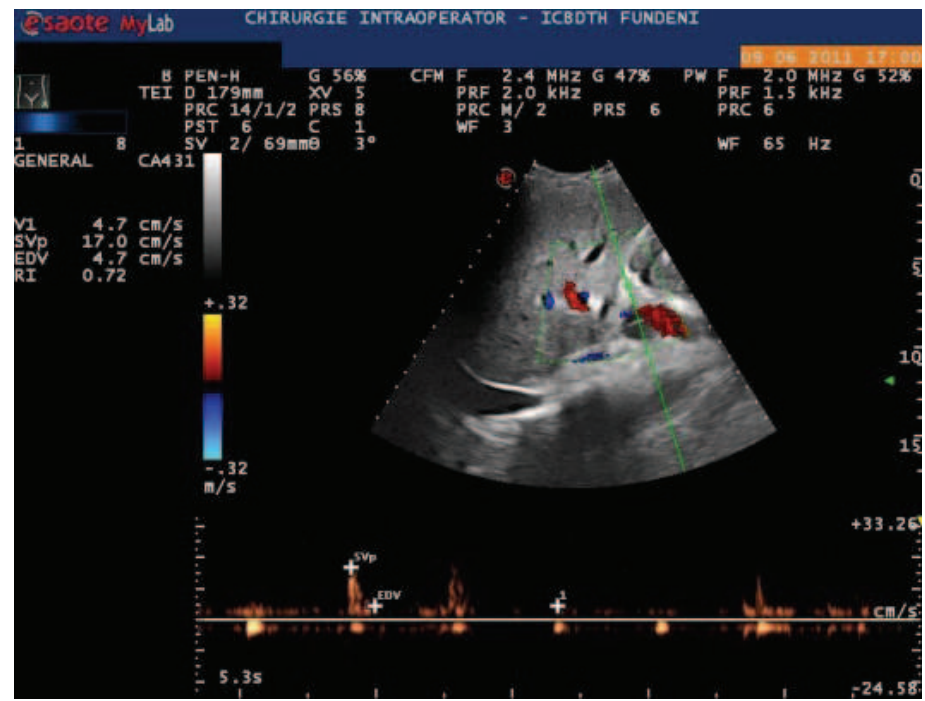

Fig. 6. IOUS with Doppler study. Resistive index (RI) 0.72 indicates stenosis of hepatic arterial anastomosis on a patient with right hepatic lobe transplantation. The intraoperator correction of arterial anastomosis was performed

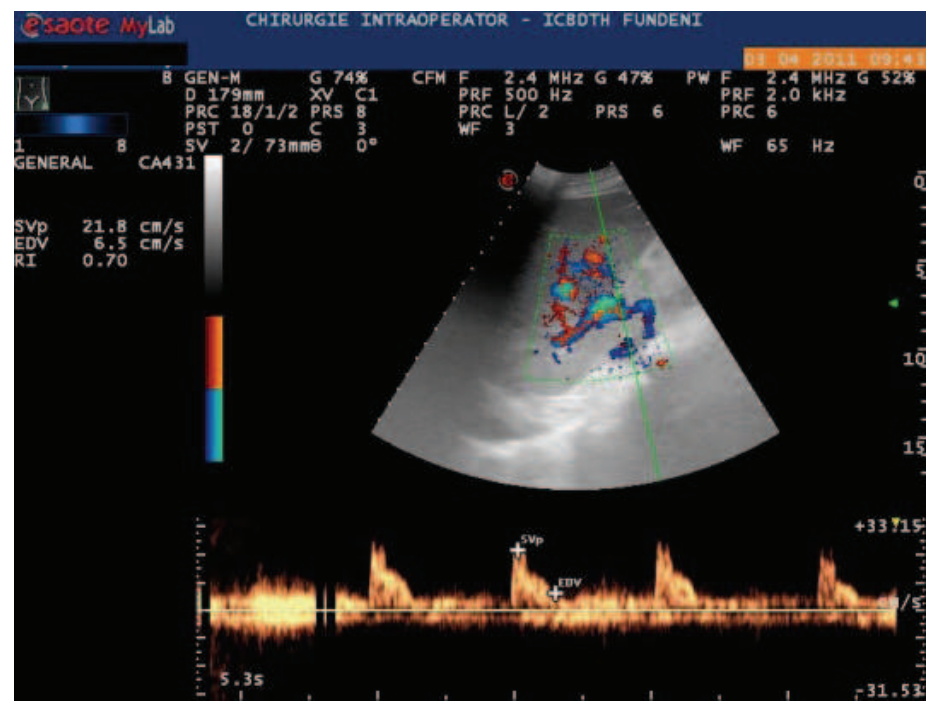

Fig. 7. Percutaneous DUS performed on a patient with right hepatic lobe transplantation on the third postoperative day shows a resistive index (RI) of hepatic artery at the upper limit of the normal. The outcome was favorable after i.v. infusion of Iloprost (Ilomedin ${ }^{\circledR}$ ) 
DUS has become the best diagnostic tool for HAT, thus surpassing angiography, which is invasive and time-consuming. Ultrasound can detect the absence of flow up to $92 \%$ of cases of hepatic artery thrombosis. Occasionally, a blunted waveform (tardus parvus arterial waveform) with resistive index $<0.5$ and acceleration time $>100$ ms may be obtained within the hepatic parenchyma. (Muradali \& Wilson, 2005) This waveform is produced by collateral arterial vessels, which may develop as early as two weeks posttransplant. A false positive diagnostic of HAT may occur with severe hepatic edema, systemic hypotension, and high-grade hepatic artery stenosis. A diminished resistance index is an indication for an arteriogram.

Percutaneous DUS follow-up is scheduled daily during the first 2 weeks posttransplant, every other day on the third week, and twice a week thereafter until discharge. After discharge DUS should be done at intervals between 6 and 12 months. A diagnosis of vessel obstruction or thrombosis made by DUS (Figure 8 ) had to be confirmed by 3D CT angiography (Figure 9). (Okochi et al., 2010) In donors who underwent 2-in-1 segmental resection of the hepatic arteries, DUS is carried out on the second postoperative day and before discharge.

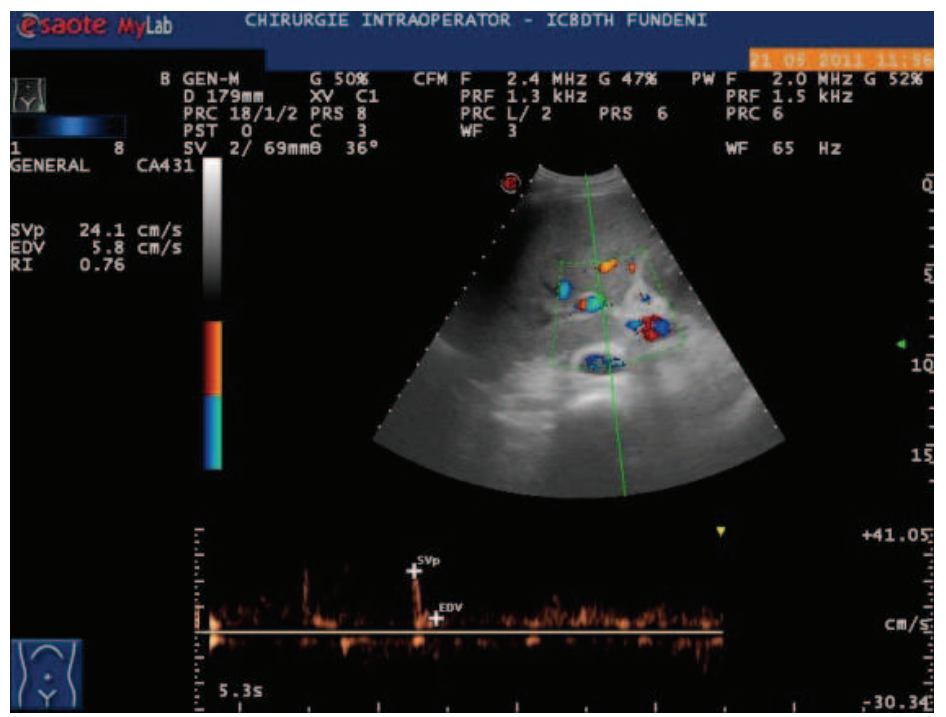

Fig. 8. Percutaneous DUS performed on a patient with right liver transplantation shows RI of 0.76 which is higher than normal suggesting HAT

DUS criteria for HAT include the following features: total absence of hepatic artery signal, absence of extrahepatic signal with intrahepatic low amplitude, delayed upstroke signal suggesting thrombosis with collateralization, direct visualization of abrupt loss of arterial signal in the extrahepatic arterial branches, visualization of arterial collaterals in the porta hepatis. Ancillary ultrasound findings that suggest HAT include parenchymal infarcts, intrahepatic bilomas or abscesses, or multifocal biliary dilatation.

Angiographic confirmation of HAT is needed if DUS diagnosis is equivocal.

Early detection of HAT by DUS with no suggestion of underlying clinical or biological factors is an indication for emergency revascularization with thrombectomy, which has 


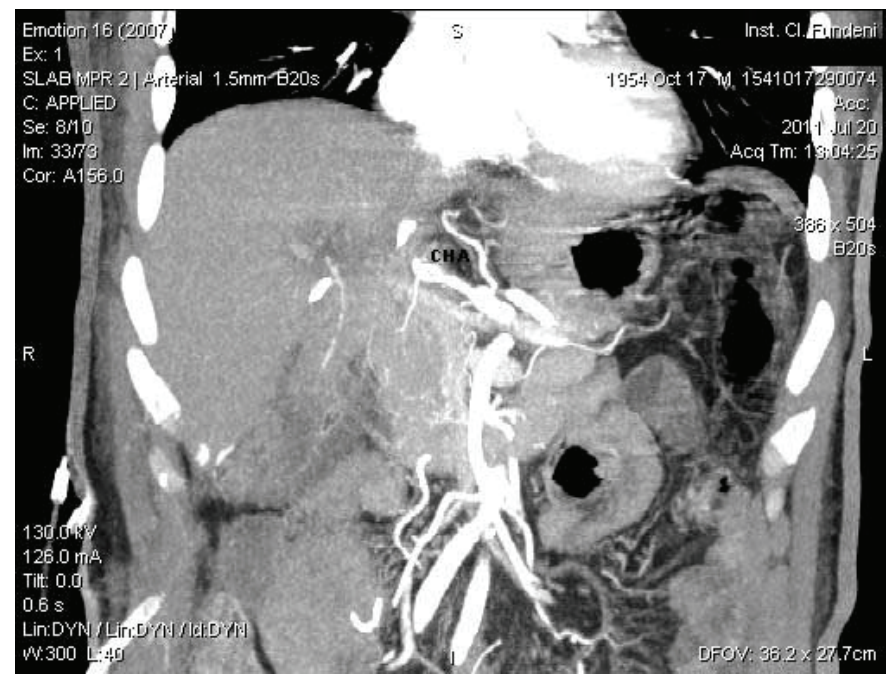

Fig. 9. 3D CT angiography confirmed complete stenosis of hepatic artery on a patient with right hepatic lobe transplantation

replaced retransplantation as the first treatment strategy for early HAT, with good rates of graft salvage and patient survival. (Nishida et al., 2002; Sakamoto et al., 1999) If recipient HA cannot be reanastomosed to the graft hepatic artery, other revascularization methods should be contemplated (e.g. anastomosis of hepatic artery with right gastroepiplooic artery (Tannuri et al., 2006), usage of a vein graft from the common iliac artery (Asakura et al., 2000) or recipient sigmoid artery (Inomoto et al., 1995).

In the past, early HAT after undergoing LT was considered uniformly fatal if the patient did not undergo urgent re-transplantation. Recently, the importance of urgent thrombectomy and revascularization has been reported. However, biliary complications, graft loss and late re-transplantation have tempered enthusiasm for this approach. The success of urgent revascularization clearly depends on early diagnosis and prompt intervention before the development of irreversible hepatic or biliary ischemia. The optimum treatment modality depends mostly on the condition of the patient, viability of the liver, availability of specific medical expertise, and availability of organ for re-transplantation, surgical revascularization, thrombolytic treatment, thrombectomy, and percutaneous transluminal balloon angioplasty with stent placement.

\subsection{Hepatic arterial stenosis}

Hepatic arterial stenosis (HAS) is the second most common arterial complication that occurs between few days to several months posttransplant. Critical hepatic artery stenosis (HAS) is considered mainly as a result of technical error and is characterized by $30 \%$ reduction in the diameter of the HA. HAS frequently progresses to thrombosis. In most cases it is caused by a technical failure. The incidence of HAS after LTx is reported to be $3-11 \%$, although the introduction of microsurgery has significantly lowered the incidence of hepatic artery complications in the field of LDLT (Ulusal et al., 2006). More than 50\% of HAS involve arterial anastomosis or graft artery (donor), while recipient artery stenosis is extremely rare. 
The etiological factors for HAS are poor surgical technique, inappropriate angulation at the anastomotic site, clamp injury, excessive removal of the adventitia, intimal dissection, allograft rejection, or preservation injury, or the result of underlying liver disease. The risk factors for the development of HAS are a recipient weighing less than $10 \mathrm{~kg}$, a long cold ischemic time, an insufficient inflow, a small diameter of the artery lumen, anatomic arterial variant, or repeated anastomosis.

The diagnostic procedure for HAS is DUS. Direct evidence of HAS involves identifying and localizing a hemodynamically significant narrowing within vessel. If the stenosis is significant, peak systolic velocities will be greater than $2-3 \mathrm{~m} / \mathrm{sec}$ ), with associated turbulent flow distally. Indirect evidence of HAS includes a tardus parvus waveform anywhere within the HA (resistive index $<0.5$, acceleration time $>100 \mathrm{msec}$ ) and is more common seen in clinical practice. (Muradali \& Wilson, 2005)

Angiographic confirmation is needed if DUS shows signs of HAS because therapy for HAS depends mainly on the location and length of the stenotic segment. Angiography is also needed if clinic suspicion of HAS is high despite a normal Doppler study.

Early diagnosis of HAS with deliberated follow-up of graft arterial circulation using DUS contributes to graft salvage by preventing graft infarction or devastating biliary ischemia, and thus the compensatory growth of abundant collateral arterial flow into the liver effects better outcome of the patient, even if the HA is stenosed. Angiographic confirmation is needed in cases where DUS screening shows signs of HAS. Management of HAS depends mainly on the location and length of the stenotic segment. The initial therapy for HAS should be medical treatment with anti-coagulants, vasodilators, hyperbaric oxygen administration and correction of dehydration until collateral vessels grow in the graft. If conservative treatment fails, an interventional procedure should be considered. In the first few days posttransplant, direct surgical re-anastomosis of the HA is occasionally possible. After the first postoperative week surgical reanastomosis is often difficult and unsuccessful because of fragile artery wall tissue. A substitute for surgery in relatively short HAS is percutaneous transluminal angioplasty (PTA) and stenting. Interventional radiology can be safely and successfully applied to the treatment of vascular complications using balloon dilatation (Tanaka et al., 1993) and/or stent placement techniques before graft dysfunction becomes irreversible. (Egawa, 2004) However major complications can occur (e.g. dehiscence of the surgical anastomoses if an inappropriate size of balloon catheter is used). Moreover the long-term results remain to be evaluated in the future with such approach of treatment.

Untreated HAS carries a high morbidity rate. HA PTA have better patency rates than those associated with hepatic artery stent placement. (Saad et al., 2005) If the treatment with PTA is ineffective or stenosis is extensive, surgical revision should be performed. Retransplantation is the last resort and is indicated if there are biliary complications.

\subsection{Pseudoaneurysm of hepatic artery}

Pseudoaneurysm of hepatic artery is seldom encountered, but when occurs, it may lead to serious life threatening complications of liver transplant, especially when it ruptures. It usually develops at the site of the arterial anastomosis as result of a technical error or bacterial or fungal infection. If located intrahepatic, it indicates a relation to a needle biopsy of the transplanted liver. The rupture of an intrahepatic false aneurysm may lead toward the formation of an arterio-portal fistula with subsequent development of hyperkinetic portal 
hypertension. If a pseudoaneurysm perforates into the bile ducts, it can cause hematobilia, severe shock, or even death. Consequently, bacterial and fungal infections are also a serious threat. Diagnosis of pseudoaneurysm of hepatic artery requires a high degree of suspicion. On gray-scale ultrasound, pseudoaneurysm appears as a cystic (anechoic) periportal structure, with intense swirling flow on DUS and a disorganized spectral waveform. DUS and CT may miss the diagnosis. (Tobben et al., 1988) Any suspicion of a hepatic aneurysm mandates arteriography during which a stent placement or transcatheter arterial coil embolization of the aneurysm can be performed. (Maleux et al., 2005)

The surgical therapeutic options include: (1) resection of the pseudoaneurysm and ligation of the hepatic artery, as long as sufficient collateral circulation into the graft within 1 month after transplantation can be anticipated; (2) reconstruction of the hepatic artery using autograft interposition or bypass (e.g. cadaveric iliac artery conduit between the donor hepatic artery and the recipient aorta) (Jarzembowski et al., 2008) only if the perioperative site is not contaminated; (3) retransplantation. In anticipation of such unpredictable complication, it might be useful to preserve both hepatic arteries of the recipient in adequate length and shape.

\subsection{Arterial steal syndrome}

Arterial steal syndrome is a significant problem after liver transplantation and is characterized by arterial hypoperfusion of the graft, which is caused by a shift in blood flow into other arteries that originate from the same trunk. Most cases of steal syndrome are associated with the splenic artery which has been reported in $3.2-4 \%$ of patients. The onset of the splenic artery steal syndrome, which varies among patients, may occur either during the first few hours after liver transplantation or as late as several weeks after transplantation. If the hyperdynamic state does not improve immediately after liver transplantation, reduced splenic arterial resistance and increased splenic arterial flow may divert celiac blood flow into the spleen. In some patients, swelling of the liver develops as a result of preservation injury, which usually causes increased intrahepatic arterial resistance and further diversion of blood flow away from the hepatic artery into the splenic artery. In other patients it may be more related to the progressive increase in splenic arterial flow caused by the pre-surgical hyperdynamic state, with or without the development of clinical hypersplenism. Development of splenic artery steal syndrome might also be related to presurgical increased splenic arterial flow that is not clinically significant at the time of transplantation but is exacerbated by the rejection of the graft or by viral hepatitis. Cases of gastroduodenal artery steal syndrome have also been reported.

Dramatic recovery of the graft and LFTs after cessation of the steal makes it mandatory to consider this condition in the differential diagnosis of postoperative hepatic dysfunction.

Arterial steal syndrome is suggested by elevated levels of liver enzymes and the results of DUS and computed tomographic angiography. In steal syndrome hepatic artery is patent but characterized by sluggish flow. The filling of the intrahepatic arterial branches by contrast material is delayed in comparison with the filling of other branches of the celiac trunk. Poor peripheral hepatic parenchymal perfusion is associated with early and abundant filling of the splenic or left gastric artery, which also shows increased size and flow. The diagnosis is confirmed by angiography.

Angiography offers the possibility of therapy by transcatheter splenic or left gastric artery occlusion with metallic coils or by placement of an endoluminal narrowing stent. The result 
is checked by angiography. In each patient, vital signs should be monitored, LFTs reassessed, and DUS scheduled twice a day for 2 days and then once a day for 1 week. Significant recovery of the graft and LFTs after cessation of the steal syndrome makes mandatory to consider it in the differential diagnosis of postoperative hepatic dysfunction.

\section{Conclusions}

Anatomical variability is the rule rather than the exception in liver transplantation. Hepatic arterial reconstruction is one of the most difficult procedures in LDLT. HA reconstruction in LDLT is more complex in left grafts when compared with right grafts due to a higher incidence of multiple arteries in the former. This problem is surmounted by meticulous perioperative planning, intraoperative surgical innovations, and postoperative close followup. Currently, dynamic contrast material-enhanced CT and MR imaging have replaced other imaging tests for preoperative evaluation. Surgeons who perform hepatic arterial reconstruction in LDLT should be highly trained in microvascular techniques. In LDLT with right lobe microvascular arterial anastomosis is not necessary, and vascular complications should be infrequent. In LDLT with left liver microsurgical techniques are a requisite that enables the reconstruction of arteries with reduced diameter or caliber difference, and thus decreases arterial complications. With the implementation of broadly applicable, practical, surgical techniques for arterial reconstruction, LDLT would be less laborious and with more consistent results and no contraindication for LDLT should be affirmed based on anatomical variants of arterial vasculature of the liver. Close surveillance of the vascular anastomoses and multidisciplinary approach to the treatment of vascular complication after LRLT considerably reduces graft loss and patient mortality. Gray-scale sonography coupled with color Doppler is the best first intention screening examination to be performed after hepatic transplantation. Arteriography not only remains the key examination for the diagnosis and evaluation of these complications but also has proved to be a graft-saving approach in the treatment of arterial complications.

\section{References}

Cheng, Y.F.; Chen, C.L.; Huang, T.L.; Chen, T.Y.; Lee, T.Y.; Chen, Y.S.; Wang, C.C.; de, Villa, V., Goto, S.; Chiang, Y.C.; Eng, H.L.; Jawan, B. \& Cheung, H.K. Single imaging modality evaluation of living donors in liver transplantation: magnetic resonance imaging. Transplantation, Vol.72, No.9 , (November 2001), pp:1527-1533, ISSN 15340608

Coskun, M.; Kayahan, E.M.; Ozbek, O.; Cakir, B.; Dalgic, A. \& Haberal, M. Imaging of hepatic arterial anatomy for depicting vascular variations in living related liver transplant donor candidates with multidetector computed tomography: comparison with conventional angiography. Transplant Proc, Vol.37, No.2, (March 2005), pp:1070-1073, ISSN 0041-1345

De Candia, A.; Como, G.; Tedeschi, L.; Zanardi, R.; Vergendo, M.; Rositani, P. \& Bazzocchi, M. Color Doppler sonography of hepatic artery reconstruction in liver transplantation. Journal Clinical Ultrasound, Vol.30, No.1, (January 2002), pp:12-17, ISSN 1097-0096

Di Benedetto, F.; Lauro, A.; Masetti, M.; Cautero, N.; Quintini, C.; Dazzi, A.; Ramacciato, G.; Risaliti, A.; Miller, C.M. \& Pinna, A.D. Use of a branch patch with the cystic artery 
in living-related liver transplantation. Clin Transplant, Vol.18, No.4, (August 2004), pp:480-483, ISSN 1399-0012

Egawa H. [Application of interventional radiology for stenosis of vascular anastomosis in living-donor liver transplantation]. Nippon Geka Gakkai Zasshi, Vol.105, No.6, (June 2004), pp:364-368, ISSN 0301-4894

Enne, M.; Pacheco-Moreira, L.; Balbi, E.; Cerqueira, A.; Alves, J.; Valladares, M.A.; Santalucia, G. \& Martinho, J.M. Hepatic artery reconstruction in pediatric living donor liver transplantation under $10 \mathrm{~kg}$, without microscope use. Pediatr Transplant, Vol.14, No.1, (February 2010), pp:48-51, ISSN 1399-3046

Ersoz, S.; Tuzuner, A.; Hazinedaroglu, S.; Karayalcin, K.; Yerdel, M.A. \& Anadol, E. Could the use of interposition grafts for arterial reconstruction be avoided by more caudate graft placement in living donor liver transplantation? Transplant Proc, Vol.35, No.4, (June 2003), pp:1427-1429, ISSN 0041-1345

Guarrera, J.V.; Sinha, P.; Lobritto, S.J.; Brown, R.S. Jr., Kinkhabwala, M. \& Emond, J.C. Microvascular hepatic artery anastomosis in pediatric segmental liver transplantation: microscope vs loupe. Transpl Int, Vol.17, No. 10, (November 2004), pp:585-588, ISSN 1432-2277

Haberal, M.; Sevmis, S.; Karakayali, H.; Moray, G.; Yilmaz, U.; Ozcay, F.; Torgay, A.; Aydogan, C. \& Arslan, G. A novel technique for hepatic arterial reconstruction in living-donor liver transplant. Exp Clin Transplant, Vol.5, No. 1, (June 2007), pp:585589, ISSN 1304-0855

Heffron, T.G.; Pillen, T.; Welch, D.; Smallwood, G.A.; Redd, D. \& Romero, R. Hepatic artery thrombosis in pediatric liver transplantation. Transplant Proc, Vol.35, No.4, 2003, (June 2003), pp:1447-1448, ISSN 0041-1345

Ikegami, T.; Masuda, Y.; Ohno, Y.; Urata, K.; Nakazawa, Y.; Miwa, S.; Hashikura, Y. \& Miyagawa, S. Arterial reconstruction in a case of subintimal dissection of celiac arterial tributaries in living donor liver transplantation: a case report. Transplant Proc, Vol.40, No.10, (December 2008); pp:3794-3796, ISSN 0041-1345

Inomoto, T.; Nishizawa, F.; Sasaki, H.; Terajima, H.; Shirakata, Y.; Miyamoto, S.; Nagata, I.; Fujimoto, M.; Moriyasu, F.; Tanaka, K. \& Yamaoka, Y. Experiences of 120 microsurgical reconstructions of hepatic artery in living related liver transplantation. Surgery, Vol.119, No.1, (January 1996), pp:20-26, ISSN 0039-6060

Inomoto, T.; Nishizawa, F.; Terajima, H.; Shirakata, Y.; Yamamoto, Y.; Miyamoto, S.; Fujimoto, M.; Tanaka, K. \& Yamaoka, Y. The use of the recipient sigmoid artery for a revision of hepatic arterial reconstruction after thrombosis in living related liver transplantation. Transplantation, Vol:60, No.8, (Octomber 1995), pp:881-882, ISSN 0041-1337

Jarzembowski, T.M.; Sankary, H.N.; Bogetti, D.; Manzelli, A.; Ong, E.; Oberholzer, J.; Benedetti, E. \& Testa, G. Living donor liver graft salvage after rupture of hepatic artery pseudoaneurysm. Int Surg, Vol.93, No.5, (September 2008), pp:300-303, ISSN 0020-8868

Johnson, P.T. \& Fishman, E.K. IV contrast selection for MDCT: current thoughts and practice. AJR Am J Roentgenol, Vol.186, No.2, (February 2006), pp:406-415, ISSN 031$803 X$

Kamei, H.; Fujimoto, Y.; Yamamoto, H.; Nagai, S.; Kamei, Y. \& Kiuchi T. The use of radial artery interpositional graft between recipient splenic artery and graft artery in living donor liver transplantation. Transpl Int, Vol.19, No. 11, (November 2006), pp:945-946, ISSN 1432-2277 
Kasahara, M.; Sakamoto, S.; Ogawa, K.; Uryuhara, K.; Matsuoka, J.; Uchida, Y.; Ito, T.; Ueda, M. \&Tanaka K. The use of a mesenteric artery of Roux-en-Y limb for hepatic arterial reconstruction after living-donor liver transplantation. Transplantation, Vol.80, No.4, (August 2005), pp:538, ISSN 1543-0608

Lee, C.C.; Jeng, L.B.; Li, P.C.; Yang, H.R.; Lu, C.W.; Chen, T.H.; Cheng, H.T.; Chang, S.C.; Lin, M.S.; Poon, K.S.; Chen, Y.F. \& Ho, Y.J. Innovative technique to reconstruct two branches of the right hepatic artery in living donor liver transplantation. Transplant Proc, Vol.40, No.8, (October 2008), pp:2525-2526, ISSN 0041-1345

Lehar, S.C.; Zajko, A.B.; Koneru, B.; Stevenson, W. \& Sumkin J. Splenic infarction complicating pediatric liver transplantation: incidence and CT appearance. J Comput Assist Tomogr, Vol.14, No.3, (May 1990), pp:362-365, ISSN 1532-3145

Macdonald, D.B.; Haider, M.A.; Khalili, K.; Kim, T.K.; O'Malley, M.; Greig, P.D.; Grant, D.R.; Lockwood, G. \& Cattral MS. Relation between vascular and biliary anatomy in living liver donors. AJR Am J Roentgenol, Vol.185, No.1, (July 2005), pp:247-252, ISSN 0361-803X

Maleux, G.; Pirenne, J.; Aerts, R. \& Nevens, F. Case report: hepatic artery pseudoaneurysm after liver transplantation: definitive treatment with a stent-graft after failed coil embolisation. Br J Radiol, Vol.78, No.929, (May 2005), pp:453-456, ISSN 0007-1285

Margreiter, C.; Aigner, F.; Orozco, H.; Wechselberger, G.; Ollinger, R.; Bosmuller, C.; Sucher, R.; Mark, W. \& Margreiter, R. Hepatic artery reconstruction with inferior mesenteric vein graft in pediatric living donor liver transplantation. Pediatr Transplant, Vol.12, No.3, (May 2008), pp:324-328, ISSN ISSN 1399-3046

Matsuda, H.; Yagi, T.; Sadamori, H.; Matsukawa, H.; Shinoura, S.; Murata, H; Umeda, Y. \& Tanaka N. Complications of arterial reconstruction in living donor liver transplantation: a single-center experience. Surg Today, Vol.36, No.3, (2006), pp:245251, ISSN 0941-1291

Miyagi, S.; Enomoto, Y.; Sekiguchi, S.; Kawagishi, N.; Sato, A.; Fujimori, K. \& Satomi, S. Microsurgical back wall support suture technique with double needle sutures on hepatic artery reconstruction in living donor liver transplantation. Transplant Proc, Vol.40, No.8, (October 2008), pp:2521-2522, ISSN 0041-1345

Mun, H.S.; Kim, K.W.; Song, G.W.; Ahn, C.S.; Kim, S.Y; Hwang, S. \& Lee, S.G. Evaluation of the hepatic artery anastomosis by intraoperative sonography with high-frequency transducer in right-lobe graft living donor liver transplantation. Journal Clinical Ultrasound, Vol.38, No.1, (January 2010), pp:10-16, ISSN 1097-0096

Muradali, D. \& Wilson, S. (2005). Organ transplantation, In Diagnostic ultrasound, Rumack, C.; Wilson, S.; Charboneau, J., (Eds), 657-701, Elsevier Mosby, ISBN 0323020232

Okochi, M; Ueda, K.; Hirose, T.; Okochi, H.; Watanabe, H.; Suzuki, Y. \& Kajikawa A. A modified technique for hepatic artery reconstruction in living donor liver transplantation. Microsurgery, Vol.30, No.7, (October 2010), pp:541-544, ISSN 07381085

Renz, J.F. \& Busuttil, R.W. Adult-to-adult living-donor liver transplantation: a critical analysis. Semin Liver Dis, Vol.20, No.4, (2000), pp:411-424, ISSN 0272-8087

Saad, W.E.; Davies, M.G.; Sahler, L.; Lee, D.E.; Patel, N.C.; Kitanosono, T.; Sasson, T. \& Waldman, D.L. Hepatic artery stenosis in liver transplant recipients: primary treatment with percutaneous transluminal angioplasty. J Vasc Interv Radiol, Vol.16, No.6, (June 2005), pp:795-805, ISSN 1051-0443

Sahani, D.; D'souza, R.; Kadavigere, R.; Hertl, M.; McGowan, J.; Saini, S. \& Mueller, P.R. Evaluation of living liver transplant donors: method for precise anatomic definition 
by using a dedicated contrast-enhanced MR Imaging Protocol. RadioGraphics, Vol.24, No.4, (July0August 2004), pp: 957-967 ISSN 02171-5333

Sakamoto, Y.; Harihara, Y.; Nakatsuka, T.; Kawarasaki, H.; Takayama, T.; Kubota, K.; Kimura, W.; Kita, Y.; Tanaka, H.; Ito, M.; Hashizume, K. \& Makuuchi M. Rescue of liver grafts from hepatic artery occlusion in living-related liver transplantation. $\mathrm{Br} \mathrm{J}$ Surg, Vol.86, No.7, (July 1999), pp:886-889, ISSN 0007-1323

Stell, D.; Downey, D.; Marotta, P.; Solano, E.; Khakhar, A.; Quan, D.; Ghent, C.; McAlister, V. \& Wall W. Prospective evaluation of the role of quantitative Doppler ultrasound surveillance in liver transplantation. Liver Transpl, Vol.10, No.9, (September 2004), pp:1183-1188, ISSN 1527-6465

Stemmler, B.J.; Paulson, E.K.; Thornton, F.J.; Winters, S.R.; Nelson, R.C. \& Clary, B.M. Dualphase 3D MDCT angiography for evaluation of the liver before hepatic resection. AJR Am J Roentgenol, Vol.183, No.6, (December 2004), pp:1551-1557, ISSN 0361-803X

Tanaka, K.; Uemoto, S.; Tokunaga, Y.; Fujita, S.; Sano, K.; Nishizawa, T.; Sawada, H.; Shirahase, I.; Kim, H.J. \& Yamaoka, Y. Surgical techniques and innovations in living related liver transplantation. Ann Surg, Vol.217, No.1, (January 1993), pp:8291, ISSN 0003-4932

Tannuri, U.; Maksoud-Filho, J.G.; Silva, M.M.; Suzuki, L.; Santos, M.M.; Gibelli, N.E.; Ayoub, A.A.; Velhote, M.C.; Pinho-Apezzato, M.L. \& Maksoud, J.G. An alternative method of arterial reconstruction in pediatric living donor liver transplantation with the recipient right gastroepiploic artery. Pediatr Transplant, Vol.10, No.1, (February 2006), pp:101-104, ISSN 1399-3046

Tobben, P.J.; Zajko, A.B.; Sumkin, J.H.; Bowen, A.; Fuhrman, C.R.; Skolnick, M.L.; Bron, K.M.; Esquivel, C.O. \& Starzl T.E. Pseudoaneurysms complicating organ transplantation: roles of CT, duplex sonography, and angiography. Radiology, Vol.169, No.1, (October 1988), pp:65-70, ISSN 0033-8419

Uchiyama, H.; Harada, N.; Sanefuji, K.; Kayashima, H.; Taketomi, A.; Soejima, Y.; Ikegami, T.; Shimada, M. \& Maehara, Y. Dual hepatic artery reconstruction in living donor liver transplantation using a left hepatic graft with 2 hepatic arterial stumps. Surgery, Vol.147, No.6, (June 2010), pp:878-886, ISSN 0039-6060

Uchiyama, H.; Hashimoto, K.; Hiroshige, S.; Harada, N.; Soejima, Y.; Nishizaki, T.; Shimada, M. \& Suehiro, T. Hepatic artery reconstruction in living-donor liver transplantation: a review of its techniques and complications. Surgery, Vol.131, No.1 Suppl, (January 2002), pp:S200-S204, ISSN 0039-6060

Uchiyama, H.; Ikegami, T.; Soejima, Y.; Ninomiya, M.; Kayashima, H.; Taketomi, A.; Shirabe, K. \& Maehara, Y. Use of recipient's left hepatic artery for artery reconstruction in right lobe living donor liver transplantation with duct-to-duct anastomosis. Transplantation, Vol.89, No.8, (April 2010), pp:1016-1021, ISSN 15340608

Uchiyama, H.; Shirabe, K.; Taketomi, A.; Soejima, Y.; Ninomiya, M.; Kayashima, H.; Ikegami, T. \& Maehara, Y. Extra-anatomical hepatic artery reconstruction in living donor liver transplantation: can this procedure save hepatic grafts? Liver Transpl, Vol.16, No.9, (September 2010), pp:1054-1061, ISSN 1527-6465

Ulusal, B.G.; Cheng, M.H.; Ulusal, A.E.; Lee, W.C. \& Wei, F.C. Collaboration with microsurgery prevents arterial complications and provides superior success in partial liver transplantation. Microsurgery, Vol.26, No.7, (2006), pp:490-497, ISSN 0738-1085 


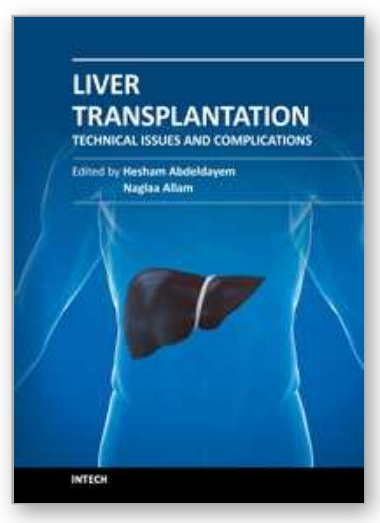

\author{
Liver Transplantation - Technical Issues and Complications \\ Edited by Prof. Hesham Abdeldayem
}

ISBN 978-953-51-0015-7

Hard cover, 454 pages

Publisher InTech

Published online 10, February, 2012

Published in print edition February, 2012

This book covers a wide spectrum of topics including, but not limited to, the technical issues in living and deceased donor liver transplant procedures, cell and experimental liver transplantation, and the complications of liver transplantation. Some of the very important topics, such as the arterial reconstruction in living donor liver transplantation, biliary complications, and the post-transplant-lymphoprolifrative disorders (PTLD), have been covered in more than one chapter.

\title{
How to reference
}

In order to correctly reference this scholarly work, feel free to copy and paste the following:

Mirela Patricia Sîrbu Boeți, Brasoveanu Vladislav, Sadiq Shoaib and Irinel Popescu (2012). Arterial Anastomosis in Living Donor Liver Transplantation, Liver Transplantation - Technical Issues and Complications, Prof. Hesham Abdeldayem (Ed.), ISBN: 978-953-51-0015-7, InTech, Available from: http://www.intechopen.com/books/liver-transplantation-technical-issues-and-complications/arterialanastomosis-in-living-donor-liver-transplantation

\section{INTECH}

open science | open minds

\section{InTech Europe}

University Campus STeP Ri

Slavka Krautzeka 83/A

51000 Rijeka, Croatia

Phone: +385 (51) 770447

Fax: +385 (51) 686166

www.intechopen.com

\section{InTech China}

Unit 405, Office Block, Hotel Equatorial Shanghai

No.65, Yan An Road (West), Shanghai, 200040, China

中国上海市延安西路65号上海国际贵都大饭店办公楼 405 单元

Phone: +86-21-62489820

Fax: +86-21-62489821 
(C) 2012 The Author(s). Licensee IntechOpen. This is an open access article distributed under the terms of the Creative Commons Attribution 3.0 License, which permits unrestricted use, distribution, and reproduction in any medium, provided the original work is properly cited. 